\title{
ASSESSMENT OF EGM2008 OVER BRITAIN USING VERTICAL DEFLECTIONS, AND THE PROBLEMS WITH HISTORICAL DATA
}

\author{
W.E. Featherstone ${ }^{1}$ and J.G. Olliver ${ }^{2}$ \\ ${ }^{1}$ Western Australian Centre for Geodesy \& The Institute for Geoscience Research, \\ Curtin University of Technology, GPO Box U1987, Perth WA 6845, Australia \\ ${ }^{2}$ Department of Earth Sciences, Oxford University, \\ South Parks Road, Oxford OX1 3AN, United Kingdom
}

\begin{abstract}
Vertical deflections synthesised from the Earth Gravitational Model 2008 (EGM2008) agree with astrogeodetic vertical deflections observed over mainland Britain to within 1.2" RMS (north-south) and $\sim 1.4 "$ RMS (east-west), which is commensurate with values reported for North America, Australia and parts of continental Europe. For this assessment in Britain, there has been the additional need to transform the observed relative vertical deflections to absolute ones. Not applying horizontal datum transformations led to spurious results, so absolute vertical deflections must always be used to assess EGMs. Three datum transformations were trialled (three-parameter, seven-parameter and OSTN02), which show similar results when considering the estimated $\sim 0.3$ " precision of these historical (1950 to 1976) astrogeodetic observations. Several other problems were encountered because of the historical nature of the data, comprising destruction of survey pillars, ambiguous station names, and a mixture of horizontal geodetic datums available in Britain.
\end{abstract}

KEYWORDS: EGM2008, vertical deflections, British geodetic datums

\section{INTRODUCTION}

The Earth Gravitational Model 2008 (EGM2008) [26, 27] has been assessed globally and regionally using a variety of control data sets, such as satellite orbits, GPS-levelling, terrestrial (land, marine and airborne) gravity anomalies and/or disturbances, and vertical deflections (e.g. [22]). Vertical deflections (aka vertical deviations) provide more powerful tests of the higher degree coefficients of an EGM [18], and can also be used to test (e.g., [34] and [14]) or to refine [7] regional geoid models.

For readers unfamiliar with vertical deflections, [18] gives a concise explanation of their subtly different definitions. Since EGM2008 is a geocentric model (cf. [19]), absolute vertical deflections are needed for its assessment. However, historical astrogeodetic vertical deflections usually refer to local horizontal geodetic datums and their associated reference ellipsoids. These are termed relative vertical deflections (cf. [18]) and were used for astrogeodetic levelling to determine the separation between the geoid and the local reference ellipsoid (e.g., [1]). These local geoid models were needed for the rigorous reduction of geodetic data to the local ellipsoid (cf. [8]). Therefore, relative deflections have to be transformed to absolute deflections if they are to be used to assess EGMs.

Vertical deflections are arguably preferable for testing EGMs in Britain because the ODN [Ordnance Datum Newlyn] vertical datum contains a significant slope (e.g. [33]), with [3] advising that the ODN should not be used for scientific purposes. [28] have isolated this to systematic errors in the levelling that generate a south-north slope of around -(20-25) $\mathrm{mm} /$ degree of latitude as well as regional distortions in ODN. As such, GPS-levelling should not really be used to test geoid models in Britain, though this has been done by, e.g., [35] and [6].

Absolute vertical deflections have previously been used to assess EGM2008 in other regions. Continental European vertical deflections were observed with digital zenith cameras that used GPS to determine geocentric coordinates and thus give absolute deflections $[34 ; 12 ; 14]$. Australian and Canadian vertical deflections are absolute because geocentric coordinates were used to re-compute them $[7 ; 4 ; 16]$. The United States vertical deflections are also absolute by applying axial rotations 
and origin shifts $[18 ; 26]$, but no scale change was applied, which will be discussed later in the context of the British deflections.

This paper will examine some methods available to transform relative deflections to absolute deflections for the purpose of assessing EGM2008 in Britain. However, this has been complicated by having to deal with historical data, such as ambiguous ground-station identification, destruction or relocation of survey pillars, and a mixture of horizontal geodetic datums in Britain, some of which have not been related to a geocentric datum. Nevertheless, the results are commensurate with those reported in North America, Australia and parts of continental Europe.

\section{DEFLECTION DATA}

The astrogeodetic vertical deflections used herein were collected by $[29 ; \mathbf{3 0} ; \mathbf{3 1}$ ] between 1950 and 1954 and the Ordnance Survey (OS) in 1953 and between 1969 and 1976 [5]. Robbins's deflections referred to an unknown geodetic network available at that time, with Appendix I of [31] noting "these deviations have been computed with current geodetic co-ordinates not adjusted for the known scale and azimuth errors of the triangulation." Therefore, we did not use his tabulated values, instead relying on the 192 relative deflections listed in Appendix B of [5], which are all relative to triangulation stations on the OSGB70(SN) [Ordnance Survey of Great Britain 1970 (Scientific Network)] horizontal geodetic datum (cf. [20]). Most of these deflections were used by [5] and [24] to generate astrogeodetic geoid models of Britain. Searching the archives at http://benchmarks.ordnancesurvey.co.uk/pls/htmldb/f?p=111:13:6255072357299077241::NO:13 indicates that around half of the astrogeodetic stations have since been destroyed, but this search was complicated by ambiguous station names.

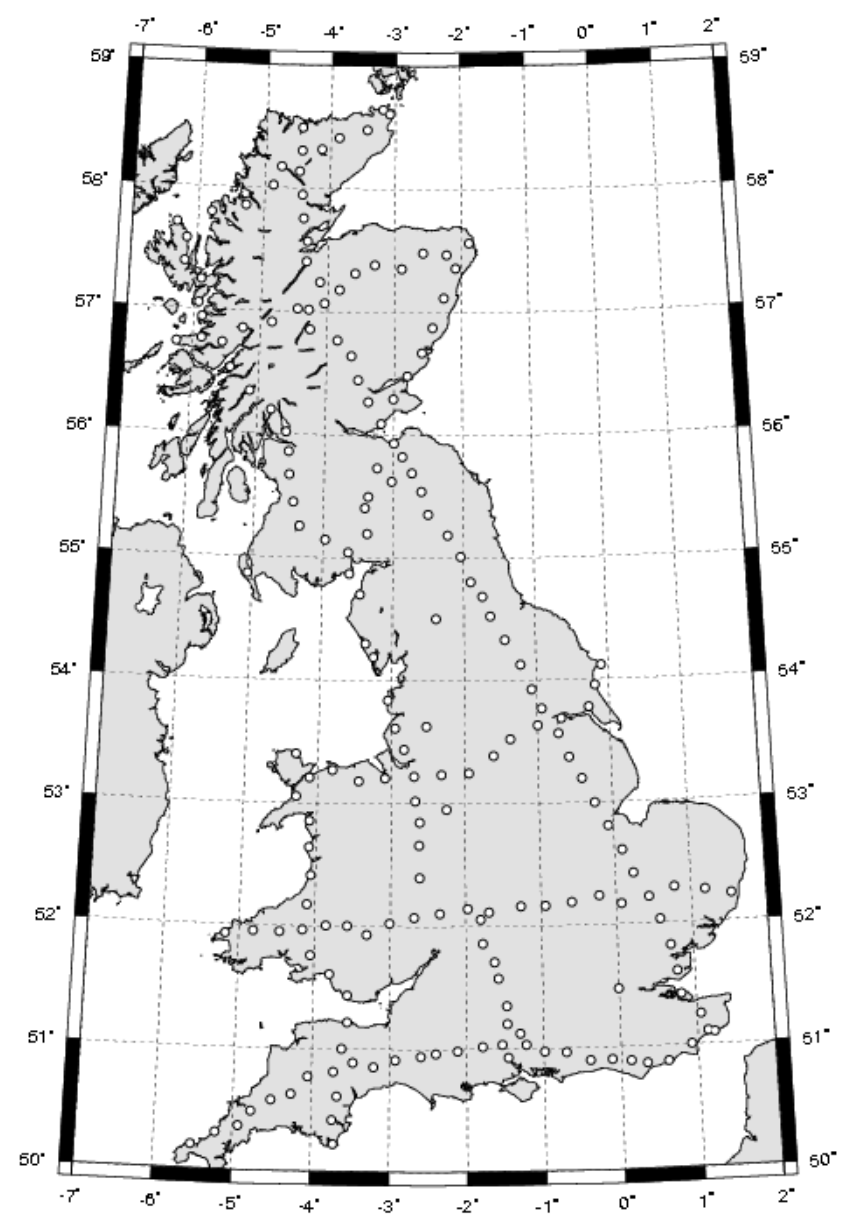

Figure 1. Coverage of the 191 astrogeodetic vertical deflections in Britain (Lambert projection) 
One additional vertical deflection was found in an archive at Oxford University, which appears to have been measured at or near Greenwich Observatory. This deflection is different to that listed in [31], suggesting that it is referred to OSGB70(SN). It was also found that [24] had omitted one of the vertical deflections listed in [5] (3135, Royal Oak). The vertical deflections at Oxford and Herstmonceux listed in [31] were - for unknown reasons - not included in [5]. As we do not have OSGB70(SN) or any other geodetic coordinates for them, these stations cannot be used with any confidence. In order to provide a fairer comparison with [24], station 3135 has been omitted and the Greenwich deflections added. Another station (3051, GS05/NM7479) presented as a consistent outlier in all comparisons, so was removed to leave 191 vertical deflections (Fig 1).

A principal problem with using these British deflections to test EGM2008 is that the horizontal geodetic coordinates refer to OSGB70(SN), whereas the transformation methods described below relate to OSGB36 [Ordnance Survey of Great Britain 1936], even though this datum contains horizontal scale errors. Therefore, we examined the difference between OSGB70(SN) and OSGB36 coordinates, but this is fraught with uncertainty as follows. The astrogeodetic station occupied was not uniquely identified, nor was information given if a reference mark was occupied (e.g. a cairn or other monument may cover the primary ground mark). Therefore, there is additional uncertainty that the correct coordinates are being transformed. This will be tested in the next section.

ODN heights of some of the astrogeodetic stations are listed in the archive at Oxford University, excepting point 3135 and the 4000-series of stations observed by Robbins (cf. [5]). It is unclear whether these are spirit levelled or determined from trigonometric heighting. From the number of decimal places quoted and the large heights of many of the stations, we infer that most are determined from trigonometric heighting, which is logical because heights of triangulation stations in Britain were rarely levelled. The ODN heights of the remaining stations were estimated using the "Google heights" application embedded in http://www.mapmate.co.uk/userzone/p/locate/s/position, which claims a precision of about $10 \mathrm{~m}$.

\section{METHODS}

As stated, relative vertical deflections have to be converted to absolute vertical deflections if they are to be used to assess geocentric EGMs. This can be done using the techniques of [18] or [24], but an arguably more direct approach is to use the geocentric geodetic coordinates of the astrogeodetic stations, as follows.

Vertical deflections, where $\xi$ is the north-south component and $\eta$ is the east-west component, are computed from co-located astrogeodetic $(\Phi, \Lambda)$ and geodetic $(\varphi, \lambda)$ coordinates using (e.g., [29; 18]):

$$
\begin{aligned}
& \xi=\Phi-\varphi+\frac{\eta^{2}}{2} \tan \varphi \\
& \eta=(\Lambda-\lambda) \cos \varphi
\end{aligned}
$$

When local geodetic coordinates are used in equations (1) and (2), they yield relative deflections, while when geocentric geodetic coordinates are used, they yield absolute deflections. Therefore, local coordinates must be transformed to geocentric coordinates in order to calculate absolute deflections. We shall experiment with the following options available in Britain. Beforehand, it is important to reiterate that the deflections were originally observed with respect to OSGB70(SN), whereas the transformations below refer to OSGB36.

\section{Three-parameter transformation}

Conceptually, a three-parameter horizontal transformation (aka Molodensky transformation) is the least accurate of the methods tested here as it only applies an origin shift, making no account for scale, rotations or regional distortions between the datums. Since [25] does not provide Molodensky transformation parameters, the OSGB36 to geocentric WGS84 [World Geodetic System 1984] 
parameters were taken from [23] as $\Delta \mathrm{X}=+(375 \pm 10) \mathrm{m}, \Delta \mathrm{Y}=-(111 \pm 10) \mathrm{m}, \Delta \mathrm{Z}=+(431 \pm 15) \mathrm{m}$. The large uncertainty of these parameters reflects the lower accuracy of this method.

\section{Seven-parameter transformation}

The seven-parameter transformation advances on the three-parameter model by accounting for axial rotations and a single scale factor, but it does not attempt to model regional distortions between datums. The parameters from OSGB36 to the geocentric ETRS89 [European Terrestrial Reference System 1989] were computed by [25] as $\Delta \mathrm{X}=446.448 \mathrm{~m}, \Delta \mathrm{Y}=-125.157 \mathrm{~m}, \Delta \mathrm{Z}=542.060 \mathrm{~m}, \mathrm{rx}=$ $0.1502 ”$, ry $=0.2470 ”, \mathrm{rz}=0.8421 ", \mathrm{ds}=20.4894 \mathrm{ppm}$. No uncertainties are provided for these parameters, but [25] gives a blanket estimate of $5 \mathrm{~m}$ accuracy for this transformation. When applying the seven-parameter transformation, care is also needed to apply the axial rotations with the correct sign convention [32]. The large scale parameter of $\sim 20 \mathrm{~mm} / \mathrm{km}$ reflects the distortion in OSGB36 (cf. $[\mathbf{2 0} ; \mathbf{3 0}])$.

\section{OSTN02 transformation}

This is the conceptually most accurate method because it also attempts to model regional distortions between datums. [25] and [10] describe the OSTN02 [Ordnance Survey National Grid Transformation 2002] model that transforms coordinates from OSGB36 to ETRS89. It requires British-National-Grid-projected OSGB36 coordinates and applies northing and easting shifts interpolated from a 1-km-resolution grid. We used the GridInQuest software (version 7.0.0 build 4737) to transform OSGB70(SN) eastings and northings to ETRS89 geodetic longitudes and latitudes. The GridInQuest software help pages indicate a transformation accuracy (one sigma) of $0.1 \mathrm{~m}$, which appears to be derived from [10].

\section{Transformation comparisons}

In an attempt to quantify the relative performance of the above transformations, as well as to determine the additional uncertainty introduced by using OSGB70(SN) instead of OSGB36, we made the following comparisons. We searched for 'GPS-observed' ETRS89 coordinates of the passive stations of the OS's GPS network (http://gps.ordnancesurvey.co.uk/passive.asp) for seemingly co-located stations. This only delivered 21 of 192 stations, but also highlighted the undesirable ambiguity regarding station names (e.g., 1011 Rottington and 3011 Malvern), reducing the number of reliably co-located stations to 14 . Such a small sample has to be used with caution.

Table 1. Differences between transformed OSGB70(SN) and 'GPS-observed' ETRS89 coordinates at 14 reliably co-located astrogeodetic stations.

\begin{tabular}{lrr}
\hline Latitude difference (") & Mean & RMS \\
\cline { 1 - 3 } Three-parameter transformation & 0.22 & \pm 0.23 \\
Seven-parameter transformation & 0.03 & \pm 0.09 \\
OSTN02 transformation & $\underline{0.03}$ & \pm 0.07 \\
\cline { 1 - 3 } & & \\
\cline { 1 - 2 } Longitude difference (") & Mean & RMS \\
\cline { 1 - 2 } Three-parameter transformation & -0.02 & \pm 0.03 \\
Seven-parameter transformation & -0.06 & \pm 0.12 \\
OSTN02 transformation & $\underline{-0.06}$ & $\underline{ \pm 0.09}$ \\
\cline { 1 - 2 } & & \\
\cline { 1 - 2 } Linear difference (m) & Mean & RMS \\
\cline { 1 - 2 } Three-parameter transformation & 7.02 & \pm 7.41 \\
Seven-parameter transformation & 5.46 & \pm 6.50 \\
OSTN02 transformation & $\underline{4.21}$ & \pm 4.93 \\
\hline
\end{tabular}


The mean and RMS coordinate differences in Table 1 are presented in terms of angular measure of latitude difference and longitude difference scaled by meridional convergence (cf. equation 2) so as to allow for easier comparison with the deflections. To convert to a linear offset in metres on the ground, these have been multiplied by $31 \mathrm{~m}$ and combined with Pythagoras. Still acknowledging the small sample size, Table 1 shows that the relative accuracy of the transformations concurs with expectation. However, there remains a bias of several metres. The most plausible explanation for this is the scale error in the OSGB36 with respect to OSGB70(SN), which will be elaborated upon at the end of the section on "Results and Discussion".

\section{EGM2008 syntheses}

Absolute Helmert vertical deflections (i.e., geocentric and at the Earth's surface) were synthesised from the tide-free EGM2008 coefficients using the transformed geocentric coordinates from the three methods described above and ellipsoidal heights of the astrogeodetic stations by adding OSGM02 [Ordnance Survey Geoid Model 2002] to the ODN heights. OSGM02 has been fitted to the ODN using GPS at benchmarks and least squares collocation [9; 17], so accounts for the systematic errors in the ODN [28], thus giving a more accurate transformation of ODN heights to ellipsoidal heights. Ellipsoidal heights are necessary to synthesise EGM2008 vertical deflections on the Earth's surface as shown in Table 5 of [15] and to apply an additional correction for the curvature of the normal plumbline, which will be described in the following section. EGM2008 values were calculated with respect to the GRS80 [Geodetic Reference System 1980] reference ellipsoid [21], which is used with ETRS89.

\section{Other corrections}

[18] describes a series of small, but some of which are systematic, conversion terms that have to be applied to make vertical deflections synthesised from an EGM compatible with Helmert astrogeodetic deflections at the Earth's surface. Jekeli's terms for the origin translations and axial rotations are not needed here because these have already been accounted for by the above datum transformations. However, Jekeli omits a correction term for the scale parameter in the sevenparameter transformation, which will be addressed at the end of the section on "Results and Discussion".

Plumbline curvature: The largest conversion term accounts for the north-south curvature of the normal plumbline, and is given by [18]

$\delta \xi_{\text {norm.curv }} \approx 0.17 h_{k m} \sin 2 \varphi \quad[\operatorname{arcsec}] \quad \delta \eta_{\text {norm.curv }}=0$

As we have the [albeit transformed] ellipsoidal heights of the astrogeodetic stations, this term can be applied directly.

Permanent tides: Although not documented in [5], it is assumed that the Helmert astrogeodetic vertical deflections are in the mean tide system (cf. [18]). Applying the Love and Shida numbers for the elastic response of the Earth to the permanent tides, the conversion from mean tide to tide-free vertical deflections (and thus compatible with the tide-free release of EGM2008) is [18]

$\delta \xi_{\text {perm.tide }}=0.012 \sin 2(\varphi-v) \quad[\operatorname{arcsec}] \quad \delta \eta_{\text {perm.tide }}=0$

where

$v \approx f(1-f / 2) \sin 2 \varphi \quad[\mathrm{rad}]$

and $f=1 / 298.257222101$ is the flattening of the GRS80 reference ellipsoid [21].

Approximation corrections: Sections 3 and 5 of [18] derive two other conversion terms for the approximations made in the spherical harmonic synthesis of vertical deflections: one is for an approximation of gravity; the other is for the misalignment between the ellipsoidal surface normal and the geocentric radial. These conversions are respectively 


$$
\begin{array}{llll}
\delta \xi_{g} \approx \xi \frac{\Delta g_{P}}{\gamma_{Q}} & {[\operatorname{arcsec}]} & \delta \eta_{g} \approx \eta \frac{\Delta g_{P}}{\gamma_{Q}} & \text { [arc sec }] \\
\delta \xi_{v}=v \frac{\delta g_{P}}{\gamma_{Q}} & {[\mathrm{rad}]} & \delta \eta_{v}=0
\end{array}
$$

where $\Delta g_{P}$ is the Molodensky free-air gravity anomaly on the Earth's surface and $\delta g_{P}$ is the gravity disturbance, also evaluated on the Earth's surface, and $\gamma_{Q}$ is normal gravity on the ellipsoid's surface, computed by [21]

$$
\gamma_{Q}=\gamma_{a} \frac{1+k \sin ^{2} \varphi}{\sqrt{1-e^{2} \sin ^{2} \varphi}}\left[\mathrm{ms}^{-2}\right]
$$

where, for GRS80, $k=0.001931851353$ is the normal gravity constant, $\gamma_{a}=9.7803267715 \mathrm{~ms}^{-2}$ is normal gravity on the equator, and $e^{2}=0.00669438002290$ is the square of the first numerical eccentricity. To evaluate these correction terms, the gravity disturbance and Molodensky free-air gravity anomaly were synthesised from EGM2008 at the 3D geocentric geodetic coordinates of the astrogeodetic stations.

Table 2. Descriptive statistics (") of Jekeli's conversion terms [18] when applied to the 191 astrogeodetic stations in Britain.

\begin{tabular}{lrrrrr}
\hline Correction term & Max & Min & Mean & STD & RMS \\
\hline$\delta \xi_{\text {norm.curv }}$ & 0.142 & 0.008 & 0.032 & \pm 0.022 & \pm 0.038 \\
$\delta \xi_{\text {perm.tide }}$ & 0.012 & -0.012 & 0.000 & \pm 0.009 & \pm 0.009 \\
$\delta \xi_{g}$ & $<0.001$ & $<0.001$ & $<0.001$ & $<0.001$ & $<0.001$ \\
$\delta \xi_{,}$ & 0.020 & -0.022 & 0.002 & \pm 0.008 & \pm 0.008 \\
$\delta \eta_{g}$ & 0.001 & $<0.001$ & $<0.001$ & $<0.001$ & $<0.001$
\end{tabular}

Table 2 shows that the above conversion terms are generally small, but the normal curvature and permanent tide contributions are systematic in a north-south direction, acting to reduce the mean difference of the north-south deflection component [18].

\section{RESULTS AND DISCUSSION}

The first row of Table 3 shows the descriptive statistics of the differences when the EGM2008 deflections are synthesised at the OSGB70(SN) station locations and compared to the relative Helmert astrogeodetic deflections. Conceptually this is incorrect, but is presented only to show the effect of not using compatible deflections. The large bias and RMS values demonstrate that relative deflections must never be used to assess EGMs. The mean deflection differences in Table 3 indicate the mean slopes of the geoid relative to the Airy 1830 spheroid compared to the geocentric geoid modelled by EGM2008 with respect to GRS80. Therefore, deflection corrections are needed if reducing terrestrial geodetic survey data to ETRS89 in Britain (cf. [8]).

After application of the conversion terms in Table 2, the EGM2008 deflections were subtracted from the absolute Helmert astrogeodetic deflections that were recomputed (equations 1 and 2) using geocentric geodetic coordinates from: (i) three-parameter-transformed OSGB70(SN) to WGS84; (iii) seven-parameter-transformed OSGB70(SN) to ETRS89; and (iv) OSTN02-transformed OSGB70(SN) to ETRS89. The results of [24] are also included in Table 3, which are similar to the three-parameter transformation, but applied at the origin of the network. The conversion terms in Table 2 were not applied to the results of [24]. 
No statistical outlier rejection was applied, apart from the one station (3051, GS05/NM7479) that was consistently out by $\sim 4 "(\sim 125 \mathrm{~m}$ on the ground) in each deflection component for all transformation methods tested. This suggests that a different ground mark may have been occupied. The RMS differences for the east-west deflections $(\eta)$ are slightly worse than the north-south deflections $(\xi)$ in Table 3, which fits with expectation because of timing uncertainties, especially for astrogeodetic observations made in the 1950s. The same feature occurs for astrogeodetic deflections used to assess EGM2008 in the United States and Australia (Table 9 of [26]) and Canada (Table 4 of [16]). The omission error in EGM2008 is included implicitly in the statistics in Table 3 (cf. [18; 15; 16]). Another smaller contributor is the accuracy of the FK4 star catalogue used to calculate the astrogeodetic deflections [5], which may contain biases of 0.05-0.10" [2].

Table 3. Descriptive statistics (") of 191 Helmert astrogeodetic deflections minus EGM2008 in Britain after application of the correction terms in Table 2.

\begin{tabular}{|c|c|c|c|c|c|}
\hline$\xi$ minus EGM2008 (north-south) & Max & Min & Mean & STD & RMS \\
\hline Relative deflections & 7.74 & -14.93 & -4.58 & \pm 3.87 & \pm 6.01 \\
\hline Three-parameter transformation & 3.92 & -5.00 & 0.26 & \pm 1.13 & \pm 1.16 \\
\hline Seven-parameter transformation & 4.24 & -4.95 & 0.27 & \pm 1.16 & \pm 1.19 \\
\hline OSTN02 transformation & 4.32 & -4.99 & 0.28 & \pm 1.18 & \pm 1.21 \\
\hline Olliver [1992] & $\underline{3.68}$ & -5.11 & $\underline{0.10}$ & \pm 1.15 & \pm 1.15 \\
\hline$\eta$ minus EGM2008 (east-west) & Max & Min & Mean & STD & RMS \\
\hline Relative deflections & 14.47 & -10.14 & 2.22 & \pm 4.14 & \pm 4.70 \\
\hline Three-parameter transformation & 2.96 & -4.13 & -0.03 & \pm 1.30 & \pm 1.30 \\
\hline Seven-parameter transformation & 3.04 & -4.25 & -0.06 & \pm 1.33 & \pm 1.33 \\
\hline OSTN02 transformation & 2.98 & -4.25 & -0.08 & \pm 1.34 & \pm 1.35 \\
\hline Olliver [1992] & 3.02 & $\underline{-6.47}$ & $\underline{-0.03}$ & \pm 1.38 & \pm 1.38 \\
\hline
\end{tabular}

Of the transformation methods used, OSTN02 should conceptually be the superior assessor of EGM2008 (cf. Table 1), but the use of OSGB70(SN) instead of OSGB36 coordinates appears to be clouding the comparisons. Nevertheless, the RMS differences for each transformation method in Table 3 are very similar. Moreover, the differences among them are statistically insignificant given the estimated $\sim 0.3 "$ precision of the astrogeodetic observations [5].

Lastly, we turn to effect that the $\sim 20 \mathrm{~mm} / \mathrm{km}$ scale error (taken from the seven parameter transformation) assumed in the OSGB36 network (cf. $[31 ; 20]$ ) could bias the results, particularly for the mean differences in the north-south deflection component in Table 3 . Applying this scale parameter over the north-south extent of the British astrogeodetic network ( $\sim 8.5$ degrees) gives an approximate mean coordinate difference of $\sim 9 \mathrm{~m}$. Knowing that $\sim 31 \mathrm{~m}$ on the ground equates to $\sim 1$ ", this could remove $\sim 0.3 "$ from the mean differences for $\xi$ in Table 3 . However, without the exact differences between OSGB70(SN) and OSGB36, this can only remain as speculation, but the similarity of the values does render it a prime suspect.

\section{CONCLUSION AND RECOMMENDATION}

In summary, 191 absolute Helmert astrogeodetic deflections have been used to assess EGM2008 in Britain, showing RMS agreements to within 1.2" (north-south component) and 1.4" (east-west component), which is commensurate with results reported for North America [26; 16], Australia [26; 4] and parts of continental Europe [13].

This assessment required transformation of the relative deflections to absolute deflections and the consideration of small, yet some systematic, conversion terms identified by [18]. The spurious 
results achieved when a transformation was not applied demonstrate that absolute deflections must only be used to assess EGMs. As per the recommendations of [3] and [28], GPS-ODN should not be used to test EGM2008 because of the south-north systematic levelling error of $-(20-25) \mathrm{mm} /$ degree latitude and regional distortions.

The three datum transformation methods tested (three-parameter, seven-parameter and OSTN02) delivered similar results, and which are insignificantly different when considering the $\sim 0.3$ " precision of these historical (1950 to 1976) astrogeodetic observations. However, the vagaries of the British geodetic datums and the use of historical data (e.g. destruction or relocation of ground marks and ambiguous station names) may also contribute a bias. In particular, the $\sim 20 \mathrm{~mm} / \mathrm{km}$ scale error in the OSGB36 could account for the mean differences seen for the north-south deflection component (Table 3), but this remains somewhat speculative.

Since modern Helmert astrogeodetic vertical deflections have proven their utility elsewhere (e.g. [12]), the OS may wish consider to conduct a new or re-observation programme (e.g. at the active and passive stations of the GPS network) using modern astrogeodetic cameras (e.g. [13; 11]).

\section{ACKNOWLEDGEMENTS}

The reference frames component of this paper contributes, but only in part, to Australian Research Council grant FS110200045. We thank Dr Christian Hirt (Curtin University) for pre-submission comments on this manuscript and other constructive comments made by two anonymous reviewers.

\section{References}

1. Bomford, G., 1980. Geodesy (fourth edition), Clarendon Press, Oxford.

2. Bucciarelli, B., Lattanzi, M.G. and Taff, L.G., 1994. The analysis of star catalogues. 1. An intercomparison among the FK3, the FK4 and the FK5, The Astrophysical Journal 433(2): 831.844, doi: 10.1086/174692.

3. Christie, R. R., 1994. A new geodetic heighting strategy for Great Britain, Survey Review 32(252): 328-343, doi: $10.1179 / 003962694791624994$.

4. Claessens, S. J., Featherstone, W. E., Anjasmara, I. M., and Filmer, M. S., 2009. Is Australian data really validating EGM2008 or is EGM2008 just in/validating Australian data, Newton's Bulletin 4: 207-251.

5. Dean, J. D. A., 1980. The astrogeodetic determination of the geoid in Great Britain, Professional Paper New Series No. 29, Ordnance Survey, Southampton, England.

6. Featherstone, W.E. and Olliver, J.G., 1994. A new gravimetric determination of the geoid of the British Isles, Survey Review 32(254): 464-478.

7. Featherstone, W. E. and Lichti, D. D., 2009. Fitting gravimetric geoid models to vertical deflections, Journal of Geodesy 83(6): 583-589, doi: 10.1007/s00190-008-0263-4.

8. Featherstone, W. E. and Rüeger, J. M., 2000. The importance of using deviations of the vertical in the reduction of terrestrial survey data to a geocentric datum, The Trans-Tasman Surveyor 1(3): 46-61, doi: 10.1080/00050326.2000.10440341 [Erratum in The Australian Surveyor 47(1): 7]

9. Forsberg, R., Strykowski, G., Iliffe, J. C., Ziebart, M., Cross, P. A., Tscherning, C. C., Cruddace, P., Stewart, K., Bray, C. and Finch, O., 2003. OSGM02: A new geoid model of the British Isles, in: Tziavos, I.N. (ed) Gravity and Geoid 2002, Ziti Publications, Thessaloniki, Greece, pp 132-137.

10. Greaves, M., 2004. OSTN02: A new definitive transformation from GPS-derived coordinates to national grid coordinates in Great Britain, Survey Review 37(293): 502-519, doi: 10.1179/003962604791482379.

11. Hanada, H., Araki, H., Tazawa, S., Tsuruta, S., Noda, H., Asari, K., Sasaki, S., Funazaki, K., Satoh, A. and Taniguchi, H., 2012. Development of a digital zenith telescope for advanced astrometry, Science China: Physics, Mechanics and Astronomy 55(4): 723-732, doi: 10.1007/s11433-012-4673-1.

12. Hirt, C., Marti, U., Bürki, B. and Featherstone, W. E., 2010a. Assessment of EGM2008 in Europe using accurate astrogeodetic vertical deflections and omission error estimates from SRTM/DTM2006.0 residual terrain model data, Journal of Geophysical Research - Solid Earth 115, B10404, doi: 10.1029/2009JB007057.

13. Hirt C., Bürki, B., Somieski, A. and Seeber, G., 2010b. Modern determination of vertical deflections using digital zenith cameras, Journal of Surveying Engineering 136(1): 1-12, doi: 10.1061/_ASCE_SU.1943-566 5428.0000009.

14. Hirt, C., 2011. Assessment of EGM2008 over Germany using accurate quasigeoid heights from vertical deflections, GCG05 and GPS levelling, Zeitschrift für Geodaesie, Geoinformation und Landmanagement 136(3): 138-149.

15. Hirt, C., 2012. Efficient and accurate high-degree spherical harmonic synthesis of gravity field functionals at the Earth's surface using the gradient approach, Journal of Geodesy 86(9): 729-744, doi: 10.1007/s00190-012-0550-y. 
16. Huang, J. and Véronneau. M., 2009. Evaluation of the GRACE-based global gravity models in Canada, Newton's Bulletin 4: 66-72.

17. Iliffe, J. C., Ziebart, M., Cross, P. A., Forsberg, R., Strykowski, G. and Tscherning, C. C., 2003. OSGM02: A new model for converting GPS-derived heights to local height datums in Great Britain and Ireland, Survey Review 37(290): 276-293, doi: 10.1179/003962603791482587.

18. Jekeli, C., 1999. An analysis of vertical deflections derived from high-degree spherical harmonic models, Journal of Geodesy 73(1): 10-22, doi: 10.1007/s001900050213.

19. Kotsakis, C., 2008. Transforming ellipsoidal heights and geoid undulations between different geodetic reference frames, Journal of Geodesy 82(4-5): 249-260, doi: 10.1007/s00190-007-0174-9.

20. Macdonald, A. S. and Christie, R. R., 1991. From miles to millimetres: the story of geodesy at Ordnance Survey 1791-1991, Survey Review 31(241): 126-147, doi: 10.1179/003962691791485875.

21. Moritz, H., 1980. Geodetic Reference System 1980, Bulletin Géodésique 54(3): 395-405, doi: 10.1007/BF02521480.

22. Newton’s Bulletin (2009) Issue ${ }^{\circ} \mathbf{4}$, April 2009, ISSN 1810-8555, Publication of the International Association of Geodesy and International Gravity Field Service.

23. NIMA (2004) Department of Defense World Geodetic System 1984: its definition and relationships with local geodetic systems (second edition), Technical Report no. 8350.2, National Imagery and Mapping Agency, Washington, http://earth-info.nga.mil/GandG/publications/tr8350.2/wgs84fin.pdf

24. Olliver, J. G., 1992. Space-derived geoid maps of Great Britain, Survey Review 31(244): 310-320, doi: $10.1179 / 003962692791485414$.

25. OS (2010) A guide to coordinate systems in Great Britain, Ordnance Survey, Southampton, England, http://www.ordnancesurvey.co.uk/oswebsite/gps/docs/A_Guide to_Coordinate_Systems_in_Great_Britain.pdf

26. Pavlis, N. K., Holmes, S. A., Kenyon, S. C. and Factor, J. F., 2012. The development and evaluation of Earth Gravitational Model (EGM2008), Journal of Geophysical Research - Solid Earth 117, B04406, doi: 10.1029/2011JB008916.

27. Pavlis, N. K., Holmes, S. A., Kenyon, S. C. and Factor, J. F., 2013. Correction to "The development and evaluation of Earth Gravitational Model (EGM2008)", Journal of Geophysical Research - Solid Earth, doi: 10.1029/jgrb.50167

28. Penna, N. T., Featherstone, W. E., Creteaux, J. and Bingham, R. J., 2013, in press. The apparent British sea slope is caused by systematic errors in the levelling-based vertical datum, Geophysical Journal International, doi: $10.1093 /$ gji/ggt 161

29. Robbins, A. R., 1951. Deviation of the vertical, Survey Review XI(79): 28-36, doi: 10.1179/003962651791273469.

30. Robbins, A. R., 1963a. A geoidal section through Great Britain (Part 1), Survey Review XVII(128): 69-75, doi: $10.1179 / 003962663792001259$.

31. Robbins, A. R., 1963b. A geoidal section through Great Britain (Part 2), Survey Review XVII(129): 121-132, doi: $10.1179 / 003962663792001231$.

32. Soler, T. and Marshall, J., 2003. A note on frame transformations with applications to geodetic datums, GPS Solutions 7(1): 22-32, doi: 10.1007/s10291-003-0044-8.

33. Thompson, K. R., 1980. An analysis of British monthly mean sea-level, Geophysical Journal of the Royal Astronomical Society 63(1): 57-73, doi: 10.1111/j.1365-246X.1980.tb02610.x.

34. Voigt C., Denker, H. and Hirt, C., 2009. Regional astrogeodetic validation of GPS/levelling data and quasigeoid models, in: Sideris, M. G. (ed.) Observing Our Changing Earth, Springer, Berlin, pp 413-420.

35. Ziebart, M. K., Iliffe, J. C., Forsberg, R. and Strykowski, G., 2008. Convergence of the UK OSGM05 GRACEbased geoid and the UK fundamental benchmark network, Journal of Geophysical Research - Solid Earth 113, B12401, doi: 10.1029/2007JB004959. 